\title{
2010 RECENT ADVANCES IN FINANCIAL ENGINEERING
}

\author{
Proceedings of the \\ KIER-TMU International Workshop \\ on Financial Engineering 2010
}




\title{
2010 RECENT ADVANCES IN FINANCIAL ENGINEERING
}

\author{
Proceedings of the \\ KIER-TMU International Workshop \\ on Financial Engineering 2010
}

Akihabara Daibiru, Tokyo

2 - 3 August 2010

editors

Masaaki Kijima

Tokyo Metropolitan University, Japan

Chiaki Hara

Kyoto University, Japan

Yukio Muromachi

Tokyo Metropolitan University, Japan

Hidetaka Nakaoka

Tokyo Metropolitan University, Japan

Katsumasa Nishide

Yokohama National University, Japan

\section{Ne world Scientific}


This page is intentionally left blank 


\section{Published by}

World Scientific Publishing Co. Pte. Ltd.

5 Toh Tuck Link, Singapore 596224

USA office: 27 Warren Street, Suite 401-402, Hackensack, NJ 07601

UK office: 57 Shelton Street, Covent Garden, London WC2H 9HE

\section{British Library Cataloguing-in-Publication Data}

A catalogue record for this book is available from the British Library.

\section{RECENT ADVANCES IN FINANCIAL ENGINEERING 2010}

Proceedings of the KIER-TMU International Workshop on Financial Engineering 2010

Copyright (C) 2011 by World Scientific Publishing Co. Pte. Ltd.

All rights reserved. This book, or parts thereof, may not be reproduced in any form or by any means, electronic or mechanical, including photocopying, recording or any information storage and retrieval system now known or to be invented, without written permission from the Publisher.

For photocopying of material in this volume, please pay a copying fee through the Copyright Clearance Center, Inc., 222 Rosewood Drive, Danvers, MA 01923, USA. In this case permission to photocopy is not required from the publisher.

ISBN-13 978-981-4366-02-1

ISBN-10 981-4366-02-1

Printed in Singapore. 


\section{PREFACE}

This book is the Proceedings of the KIER-TMU International Workshop on Financial Engineering 2010 which was held in Tokyo in the summer of 2010 in order to exchange new ideas in financial engineering among researchers from various countries, not only from academia but also from industry.

The KIER-TMU workshop is held for two consecutive years from 2009 as a successor to "Daiwa International Workshop on Financial Engineering," which was held from 2004 to 2008, and is jointly organized by the Institute of Economic Research, Kyoto University (KIER) and the Graduate School of Social Sciences, Tokyo Metropolitan University (TMU). Financial supports from Life Risk Research Center, Doshisha University, Japan Society for Promotion of Science's Program for Grants-in Aid for Scientific Research (A) \#21241040, TMU Program for Enhancing the Quality of University Education, Selective Research Fund of Tokyo Metropolitan University and Credit Pricing Corporation are greatly appreciated.

The KIER-TMU workshop serves as a bridge between academic researchers and practitioners. We invited global leading scholars, including four keynote speakers, and various kinds of active and productive discussions were made during the workshop. Main features of the presentations at the workshop are (1) wide coverage of the research themes, (2) reporting of the most up-to-date research results, and (3) active and friendly discussions between the speakers and the audiences from academia and industry.

This book consists of eleven papers, all refereed, representing or related to the presentations at the KIER-TMU workshop. These papers are addressing stateof-the-art techniques and concepts in financial engineering. This book will be of value to the readers for the most up-to-date information about the hot topics in financial engineering and brief surveys on such topics as the basic to the forefront.

We would like to express our utmost gratitude to those who contributed their papers to the proceedings and those who kindly helped us by refereeing these papers. We would also like to thank Mr. Satoshi Kanai for editing manuscripts, and Ms. Alisha Nguyen and the editorial committee members of World Scientific Publishing Co. for their kind assistance in publishing this book.

March, 2011

Masaaki Kijima, Tokyo Metropolitan University

Chiaki Hara, Institute of Economic Research, Kyoto University

Yukio Muromachi, Tokyo Metropolitan University

Hidetaka Nakaoka, Tokyo Metropolitan University

Katsumasa Nishide, Yokohama National University 


\title{
KIER-TMU International Workshop on Financial Engineering 2010
}

\author{
Date \\ August 2-3, 2010 \\ Place \\ Akihabara Daibiru, Tokyo, Japan \\ Organizer \\ Institute of Economic Research, Kyoto University \\ Graduate School of Social Sciences, Tokyo Metropolitan University

\section{Supported by} \\ Life Risk Research Center, Doshisha University \\ Japan Society for Promotion of Science's Program for Grants-in Aid \\ for Scientific Research (A) \#21241040 \\ TMU Program for Enhancing the Quality of University Education \\ Selective Research Fund of Tokyo Metropolitan University \\ Credit Pricing Corporation

\section{Program Committee} \\ Masaaki Kijima, Tokyo Metropolitan University, Chair \\ Chiaki Hara, Kyoto University, Co-Chair \\ Yukio Muromachi, Tokyo Metropolitan University \\ Hidetaka Nakaoka, Tokyo Metropolitan University \\ Katsumasa Nishide, Yokohama National University \\ Tadashi Yagi, Doshisha University
}




\section{PROGRAM}

August, 2 (Monday)

\section{Chair: Masaaki Kijima}

10:00-10:10 Fumio Harashima, President, Tokyo Metropolitan University Opening Address

\section{Chair: Katsumasa Nishide}

10:10-10:55 Ernst Eberlein, University of Freiburg

Plenary talk: Unlimited Liabilities, Reserve Capital Requirements and the Taxpayer Put (with Dilip Madan)

10:55-11:25 Kazutoshi Yamazaki, Osaka University

On Scale Functions of Spectrally Negative Lévy Processes with Phase-Type Jumps (with Masahiko Egami)

11:25-13:00 Lunch

Chair: Yuan Tian

13:00-13:45 Arturo Kohatsu Higa, Osaka University Plenary talk: Approximations for SDE Driven by Lévy Processes

13:45-14:15 Yuji Yamada, University of Tsukuba Robust Hedging of Multivariate Derivatives Using Additive Models

14:15-14:35 Afternoon Coffee I

\section{Chair: Yuji Yamada}

14:35-15:05 Yuri Kabanov, Université de Besançon Small Transaction Costs, Absence of Arbitrage and Consistent Price Systems (with Julien Grépat)

15:05-15:35 Hideatsu Tsukahara, Seijo University Estimation of Distortion Risk Measures

15:35-16:05 Chi Chung Siu, Tokyo Metropolitan University First Passage Time under Regime Switching Jump-Diffusion Process (with Masaaki Kijima)

16:05-16:25 Afternoon Coffee II 


\section{Chair: Kazutoshi Yamazaki}

16:25-16:55 Luz Rocío Sotomayor, Georgia State University

A Regime Switching Model for the Optimal Intervention of a Central Bank in the Exchange Rate Market (with Abel Cadenillas)

16:55-17:25 Naoya Takezawa, Nanzan University

Investor Characteristics and Portfolio Value 
August, 3 (Tuesday)

\section{Chair: Yukio Muromachi}

10:00-10:45 Jean-Paul Laurent, University of Lyon

Plenary talk: Pricing CDOs with State Dependent Stochastic Recovery Rates (with Salah Amraoui, Laurent Cousot, Sébastien Hitier)

10:45-11:15 Shoji Kamimura, Reitaku University

On the State Variables for Optimal Portfolio Strategies in the Japanese Market

11:15-11:45 Yoshihiko Sugihara, Bank of Japan

An Empirical Analysis of Equity Market Expectations in the Recent Financial Turmoil Using Implied Moments and Jump Diffusion Processes (with Nobuyuki Oda)

11:45-13:00 Lunch

\section{Chair: Emmanuel Denis}

13:00-13:45 Rama Cont, CNRS \& Columbia University

Plenary talk: Measuring Contagion and Systemic Risk: Insights from Network Models

13:45-14:15 Masaaki Fukasawa, Osaka University

Model-Free Implied Volatility: From Surface to Index (with I. Ishida, N. Maghrebi, K. Oya, M. Ubukata, and K. Yamazaki)

14:15-14:45 Taro Kanatani, Shiga University

Subsampling Cumulative Covariance Estimator

14:45-15:05 Afternoon Coffee I

\section{Chair: Chiaki Hara}

15:05-15:35 James Huang, Lancaster University

Are We Extracting the True Risk Neutral Densities from Option Prices? A Question with No Easy Answer

15:35-16:05 Satoshi Kawanishi, Sophia University

The Diversity of Information Acquisition Strategies in a Noisy REE Model with a Common Signal and Independent Signals

16:05-16:25 Afternoon Coffee II 


\section{Chair: Hidetaka Nakaoka}

16:25-16:55 Emmanuel Denis, Paris-Dauphine University

Vector Valued Risk Measure Processes (with Imen Ben Tahar)

16:55-17:25 Masaaki Fujii, The University of Tokyo

Collateral Posting and Choice of Collateral Currency - Implications for Derivative Pricing and Risk Management - (with Yasufumi Shimada, Akihiko Takahashi)

\section{Chair: Hidetaka Nakaoka}

17:25-17:35 Makoto Yano, Director, Institute of Economic Research, Kyoto University

Closing Address 


\section{CONTENTS}

Preface $. \ldots \ldots \ldots \ldots \ldots \ldots \ldots \ldots \ldots \ldots \ldots \ldots \ldots \ldots \ldots \ldots \ldots \ldots \ldots, \quad v$

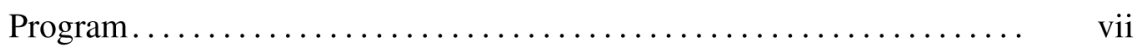

The Distribution of Returns at Longer Horizons

E. Eberlein and D. B. Madan 1

Two Examples of an Insider with Medium/Long Term Effects on the Underlying . . . . Kata and A. Kohatsu-Higa 19

A Note on the Risk Management of CDOs ..............-P. Laurent 43

Robust No Arbitrage Condition for Continuous-time Models with Transaction Costs ................................... 69

Modeling of Interest-Rate Term Structures under Collateralization and its Implications . .............. Fujii and A. Takahashi

On the State Variables for Optimal Portfolio Strategies in the Japanese Market ........................ Kamimura

The Diversity of Information Acquisition Strategies in a Noisy REE Model with a Common Signal and Independent Signals .

S. Kawanishi

Option Pricing with a Regime-Switching Lévy Model . . C. C. Siu

An Empirical Analysis of Equity Market Expectations in the Financial Turmoil Using Implied Moments and Jump Diffusion Processes... Y. Sugihara and N. Oda

Investor Characteristics and Portfolio Value N. Takezawa 